\title{
SENSE OF TIME
}

\section{Dear Reader,}

520 weeks into the future: How do you perceive this period of time that lies ahead of you - as short or long? This was one of the questions that the futurist Lars Thomsen asked decision-makers attending the AVL conference "Engine \& Environment” in Graz 2013. Most of them believed that ten years would be enough time to invent new things or even to wait and see how markets develop.

In retrospect however, many people see things differently. They feel that the past ten years went by in a flash. Therefore, Thomsen motivates engineers to use this awareness to press ahead with their developments rapidly and single-mindedly, as it might soon be too late. Even more important, he claims, is that they cultivate a sense of how trends are developing. Trends can break from one moment to the next as they reach what Thomsen refers to as "tipping points", when the pendulum suddenly swings in the opposite direction.

Ten years ago, engineers flatly rejected the idea of autonomous driving. Drivers would never let the car take over, they said. In 2003, managers in the car industry came out vehemently against hybrid drive systems, arguing that physics was being turned on its head. They might at least have taken some of the contrary opinions seriously. After all, the irreversible driving forces behind stricter emissions legislation, for example, were also acknowledged and diligently documented by the industry.

And there was certainly enough literature on the subject. In his book "Exit Future”, Frederic Vester wrote that car makers in the second millennium will not be competitive unless they not only build cars but also provide mobility. The book was based on a study by Vester commissioned by the then CEO of Ford Europe, Daniel Goeudevert.
The automotive industry is now facing such a tipping point, says Thomsen, himself a committed Tesla Model S driver. Provocatively, he sees more of a future for battery-powered electric cars than for plug-in hybrids: "Plug-in hybrids will already reach their zenith in 2017, because by then at the latest, customers will notice at the end of the month that they are proud to have driven fully electrically.”

One does not have to believe every word that Thomsen utters. But his theses certainly provoke discussions. What is the point, for example, of denigrating today's electric cars just because power stations still use brown coal? The proportion of regenerative energy will inevitably rise and be intelligently controlled. This is the future on which we must base our predictions.

The role of the media in this case is to mediate and to comment. Perhaps you might keep that in mind when reading this latest issue of ATZelektronik.

Best regards,

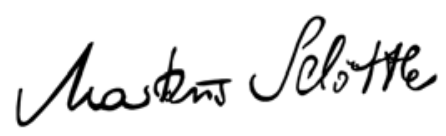

\section{MARKUS SCHÖTTLE,}

Vice-Editor in Chief

Wiesbaden, 10 March 2014

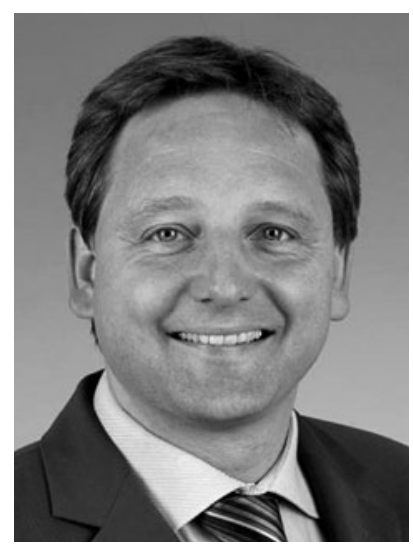

